\title{
Zs Research S Suare \\ Football and Team Handball Training Postpone Cellular Aging in Women
}

\author{
Marie Hagman \\ University of Southern Denmark \\ Bjørn Fristrup \\ University of Southern Denmark \\ Rémi Michelin \\ Karolinska Institute \\ Peter Krustrup ( $\nabla$ pkrustrup@health.sdu.dk) \\ University of Southern Denmark \\ Muhammad Asghar \\ Karolinska Institute
}

\section{Research Article}

Keywords: lifelong exercise, soccer, healthy aging, telomere length, mtDNA copy number, PGC-1a

Posted Date: March 12th, 2021

DOl: https://doi.org/10.21203/rs.3.rs-275962/v1

License: (c) (1) This work is licensed under a Creative Commons Attribution 4.0 International License.

Read Full License 
Marie Hagman $^{1}$, Bjørn Fristrup ${ }^{1,2}$, Rémi Michelin ${ }^{3}$, Peter Krustrup ${ }^{1,4,5}$, Muhammad Asghar ${ }^{3,6}$ (shared

4 last author)

5

$6{ }^{1}$ Department of Sports Science and Clinical Biomechanics, SDU Sport and Health Sciences Cluster,

7 University of Southern Denmark, Odense 5230, Denmark. ${ }^{2}$ Institute of Sports Medicine Copenhagen,

8 Bispebjerg Hospital, Copenhagen NV 2400, Denmark. ${ }^{3}$ Division of Infectious Diseases, Department

9 of Medicine Solna, Karolinska Institutet, Solna 171 64, Sweden. ${ }^{4}$ Sport and Health Sciences, St

10 Luke's Campus, University of Exeter, Exeter, EX1 6JA, United Kingdom. ${ }^{5}$ Shanghai University of

11 Sport, Shanghai, China. ${ }^{6}$ Department of Infectious Diseases, Karolinska University Hospital, Sweden.

Short title: Football and team handball postpone aging

Corresponding author:

Peter Krustrup

Professor of Sport and Health Sciences

Department of Sports Science and Clinical Biomechanics

SDU Sport and Health Sciences Cluster (SHSC)

Faculty of Health Sciences

University of Southern Denmark

Campusvej 55, Odense M-5230, Denmark

pkrustrup@health.sdu.dk

+4521161530

http://orcid.org/0000-0002-1461-9838

No disclosures or COI 


\section{ABSTRACT}

Aims: Several hallmarks of aging have been identified and examined separately in previous exercise studies. For the first time, this study investigates the effect of lifelong regular exercise in humans on two of the central aging hallmarks combined. Methods: This cross-sectional study involved 129 healthy, non-smoking women, including young elite football players (YF, $n=29$ ), young untrained controls (YC, $n=30)$, elderly team handball players $(\mathrm{EH}, n=35)$ and elderly untrained controls (EC, $n=35$ ). From a resting blood sample, mononuclear cells (MNCs) were isolated and sorted into monocytes and lymphocytes. Telomere length, mitochondrial (mtDNA) copy number and mitochondrial function (PGC-1 $\alpha$ and PGC-1 $\beta$ expression) were measured using quantitative polymerase chain reaction (qPCR). Results: Overall, young women showed significantly longer telomeres and higher mitochondrial function, but lower mtDNA copy number compared to elderly subjects. A multivariate analysis showed that YF had 22-24\% longer telomeres in lymphocytes and MNCs compared to YC. In addition, YF showed 19-20\% higher mtDNA copy number in lymphocytes and MNCs compared to YC. The two young groups did not differ in PGC-1 $\alpha$ and PGC$1 \beta$ expression. EH showed $14 \%$ lower mtDNA copy number in lymphocytes compared to EC, but 3.4-fold higher lymphocyte PGC-1 $\alpha$ expression compared to EC. In MNCs, EH also showed 1.4-1.6fold higher mitochondrial function. The two elderly groups did not differ in telomere length.

Conclusion: Elite football training and lifelong team handball training are associated with anti-aging mechanisms in leukocytes in women, including maintenance of telomere length and upregulation of mitochondrial function.

Keywords: lifelong exercise; soccer; healthy aging; telomere length; mtDNA copy number; PGC-1 $\alpha$ 


\section{INTRODUCTION}

In a time of consistent and considerable increase in global life expectancy (1), healthy aging and improved quality of life in old age are a major challenge. Aging is defined as time-dependent deterioration of the body with the passage of time that increase vulnerability to death. One of the central hallmarks of aging is telomere attrition (2). Telomeres, which are specific nucleoprotein structures capping both ends of each chromosome, function to maintain genome stability and preserve genetic information. As we age, human telomeres gradually shorten due to successive cell division and incomplete replication. When telomeres reach a critical length, the cell can no longer divide and become senescent (3). Accelerated telomere attrition has been proposed as a risk factor for several human pathologies and age-related diseases, such as chronic inflammation, infection, dementia, diabetes, cardiovascular diseases (CVD) and cancer, and for mortality in general $(4,5)$. By contrast, longer telomeres have been shown to be positively associated with more years of healthy living (6). Another important mechanism for extending both health and lifespan is maintenance of mitochondrial function. Indeed, decreased mitochondrial function, which results in impaired adenosine triphosphate (ATP) generation and increased levels of reactive oxygen species (ROS), has been implicated in driving the aging process (7). It has been found that telomere shortening and associated DNA damage promote mitochondrial dysfunction, diminished oxidative defence and compromised energygenerating processes (8). Thus, regulation of telomeres and mitochondria may be directly linked in the process of aging and in age-associated disease development.

Previous studies show that engagement in physical activity is associated with healthy aging and decreased risk of chronic diseases (9), whereas the relationship between telomere length and level of physical training is still a matter of some debate. A systematic review from 2020 showed that better cardiorespiratory fitness or a large cardiorespiratory training load are associated with longer telomeres in older healthy humans, but not in young subjects (10). This observation is in line 
with the hypothesis that telomere length is stable in young age, but begins to decline in older adulthood (11). Inconsistent findings regarding the role of exercise in telomere shortening may also be related to exercise modality. Werner et al. (12) have recently shown that 6 months of either endurance training or interval training, but not resistance training, can increase telomere length in previously inactive adults. Aerobic exercise training is also considered the gold standard for improving mitochondrial biogenesis in all age groups. In older adults, aerobe exercise training may partially reverse mitochondrial dysfunction by increasing the mitochondrial (mtDNA) copy number and volume, mitochondrial transcript and protein expression, ATP synthesis and oxidative enzyme function, while the effect of resistance training on mitochondrial function is less certain (13).

The type of exercise also appears to have a high impact on the motivation to maintain lifelong attendance. Being part of a community and developing relationships are two of the main reasons why older adults keep participating in sports (14). Team sports, such as football and team handball, are characterised by an important social factor, while combining endurance, interval and resistance training in one activity $(15,16)$. Hence, in a global strategy to increase physical activity, team sports may offer unique qualities. Whereas the topic of "Football for Health" has received much attention, with more than 150 scientific publications during the last 15 years (17), most research studies within the field of team handball have focused on injuries and performance in elite players. However, the concept of team handball training as a health-promoting activity has slowly gained interest within the last couple of years. Indeed, positive cardiovascular, skeletal and muscular adaptations have recently been observed following a short period of recreational team handball training $(18,19)$. To the best of our knowledge, no studies have investigated the potential cellular anti-aging effects of either team handball or elite football training in women. Thus, the aim of the present cross-sectional study was to examine telomere length, mtDNA copy number and 
mitochondrial function in elderly female team handball players and young female elite football 104 players in comparison with age-matched untrained women.

105

106 RESULTS

107 Telomere length

108 In total, 129 subjects were included in all the analyses. Overall, telomere length was negatively 109 correlated with age in all cell types, including lymphocytes $\left(\mathrm{r}^{2}=0.26, \mathrm{p}<0.001\right)$, monocytes $\left(\mathrm{r}^{2}=0.23\right.$, $110 \mathrm{p}<0.001)$ and MNCs $\left(\mathrm{r}^{2}=0.28, \mathrm{p}<0.001\right)$, with young subjects showing 44-54\% longer telomeres than 111 elderly subjects depending on the cell type (Fig. 1A). Our multivariate analysis corrected for age 112 showed that young football players (YF) had 24\% longer telomeres in lymphocytes compared to 113 young controls (YC) $(5.67 \pm 0.45$ vs $4.59 \pm 0.24 \mathrm{~kb}, \mathrm{p}=0.016)$ and $22 \%$ longer telomeres in MNCs 114 compared to YC $(5.12 \pm 0.33$ vs $4.21 \pm 0.19 \mathrm{~kb}, \mathrm{p}=0.010$, Fig. 1B). The elderly team handball players $115(\mathrm{EH})$ and elderly controls (EC) did not differ in telomere length in any cell types (all p>0.05, Fig. 1B, 116 Suppl. Table 1). 

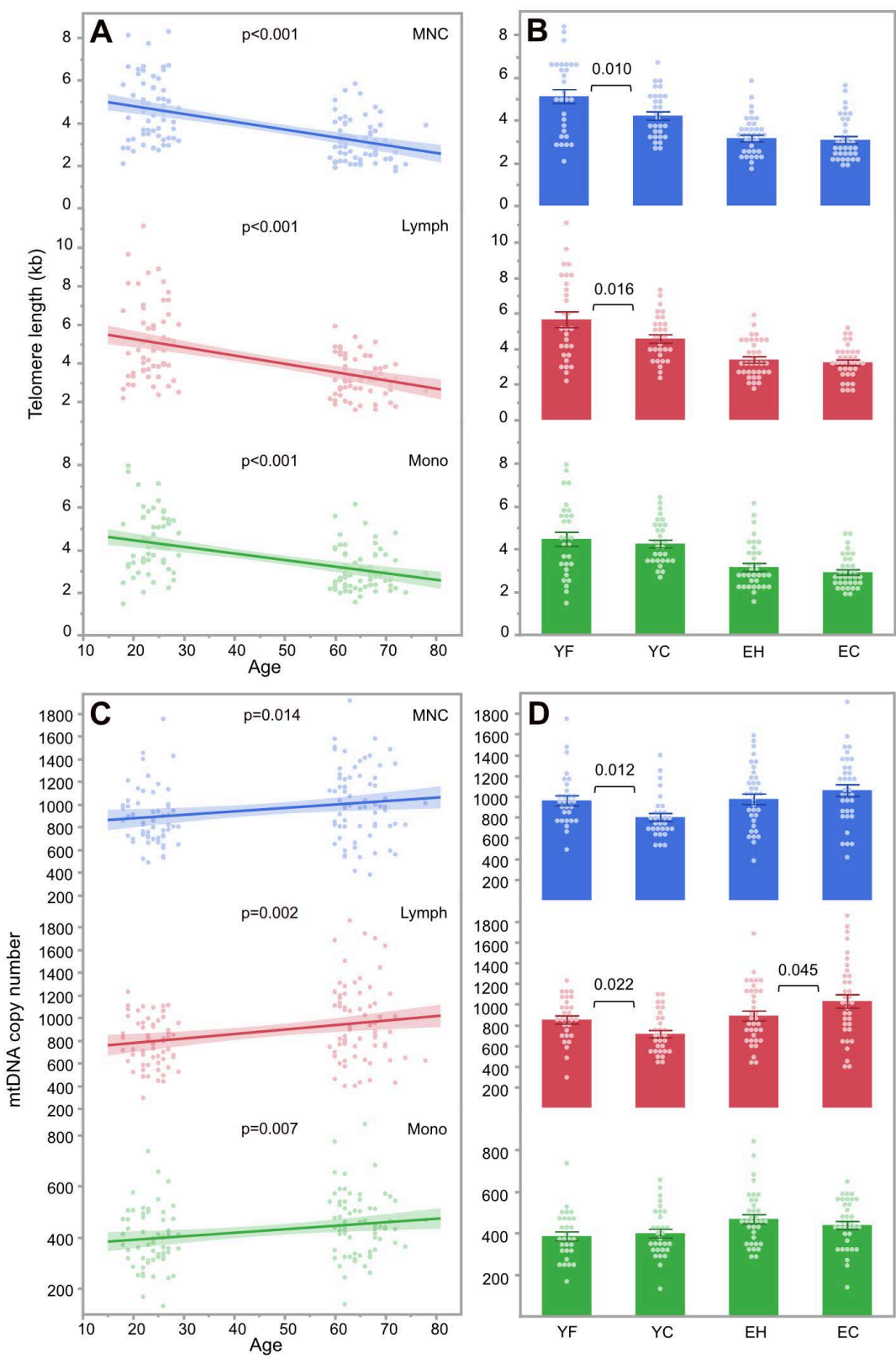

Figure 1. Correlation of telomere length with age (A) and group (B) as well as mtDNA copy number according to age (C) and group (D) in young football players (YF), young controls (YC), elderly team handball players (EH) and elderly controls (EC). Lymph, lymphocytes; MNC, mononuclear cells; Mono, monocytes.

\section{Mitochondrial copy number and function}

Overall, the mtDNA copy number was positively correlated with age in all cell types (lymphocytes: $\mathrm{r}^{2}=0.07, \mathrm{p}=0.002$; monocytes: $\mathrm{r}^{2}=0.06, \mathrm{p}=0.007$; MNCs: $\left.\mathrm{r}^{2}=0.05, \mathrm{p}=0.014\right)$, with elderly participants showing a 16-23\% higher mtDNA copy number than young participants depending on the cell type 
(Fig. 1C). On the other hand, mitochondrial function (PGC-1 $\alpha$ and PGC-1 $\beta$ expression) was negatively correlated with age in lymphocytes (PGC- $1 \alpha: \mathrm{r}^{2}=0.22, \mathrm{p}<0.001 ;$ PGC-1 $1 \mathrm{r}^{2}=0.17$, $\mathrm{p}<0.001$ ), monocytes (PGC-1 $\alpha: \mathrm{r}^{2}=0.22, \mathrm{p}<0.001 ;$ PGC-1 $\left.\beta: \mathrm{r}^{2}=0.22, \mathrm{p}<0.001\right)$ and MNCs $(\mathrm{PGC}-1 \alpha$ : $\mathrm{r}^{2}=0.20, \mathrm{p}<0.001 ; \mathrm{PGC}-1 \beta: \mathrm{r}^{2}=0.04, \mathrm{p}=0.028$ ), with young participants showing a 1.2-4.0-fold higher mitochondrial function compared to elderly participants depending on the cell type (Fig. 2A,C).

Comparison of the two young groups using multivariate analysis showed 19\% higher lymphocyte mtDNA copy number in YF compared to YC $(853 \pm 39$ vs $715 \pm 36, p=0.022)$ as well as $20 \%$ higher MNC mtDNA copy number in YF compared to YC (962 \pm 49 vs $801 \pm 38$, p=0.012, Fig. 1D, Suppl. Table 2). The expression of PGC-1 $\alpha$ and PGC-1 $\beta$ did not differ between YF and YC in any cell types (all p>0.05, Fig. 2B, D, Suppl. Table 3).

In the multivariate analysis, EH showed a 14\% lower mtDNA copy number in lymphocytes compared to EC ( $891 \pm 48$ vs $1032 \pm 65, p=0.045$, Fig. $1 D)$, while the PGC- $1 \alpha$ expression was 3.4-fold higher in the lymphocytes in $\mathrm{EH}$ compared to $\mathrm{EC}(\mathrm{p}=0.012$, Fig. $2 \mathrm{~B})$. In a univariate analysis, EH also showed 1.6-fold higher PGC-1 $\alpha$ expression in MNCs compared to EC ( $\mathrm{p}=0.041$, Fig. 2B) as well as 1.4-fold higher MNC PGC-1 $\beta$ expression compared to EC ( $p=0.044$, Fig. 2D). However, in the multivariate analysis the differences between $\mathrm{EH}$ and $\mathrm{EC}$ in mitochondrial function in MNCs only tended to be significant (PGC-1 $\alpha$ : $p=0.085$, PGC-1 $\beta$ : $p=0.089$, Suppl. Table 3). 

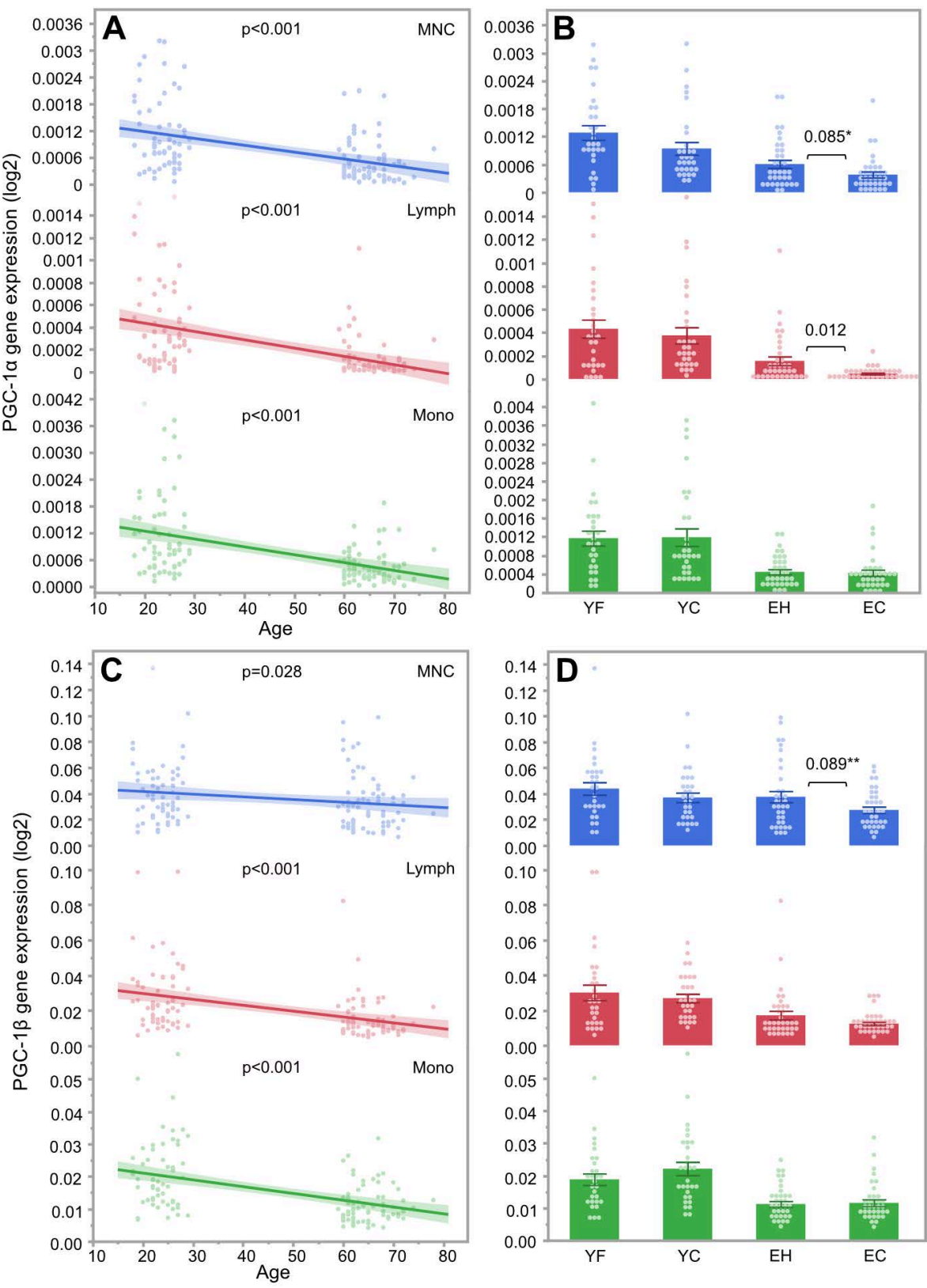

Figure 2. Correlation of mitochondrial function (PGC-1 $\alpha$ gene expression) with age (A) and group (B) as well as PGC$1 \beta$ gene expression according to age (C) and group (D) in young football players (YF), young controls (YC), elderly team

147 handball players (EH) and elderly controls (EC). Lymph, lymphocytes; MNC, mononuclear cells; Mono, monocytes. $* \mathrm{p}=0.041$ in univariate analysis; $* * \mathrm{p}=0.044$ in univariate analysis.

\section{Body composition and $\mathrm{VO}_{2 \max }$}

151 Regular team handball and football training were associated with profound improvements in body 
$153(\mathrm{p}<0.001), 32 \%$ lower android fat percentage $(\mathrm{p}<0.001), 20 \%$ lower gynoid fat percentage $(\mathrm{p}<0.001)$,

$15415 \%$ lower $\mathrm{A} / \mathrm{G}$ ratio ( $\mathrm{p}=0.017), 5.8 \mathrm{~kg}$ higher total lean mass $(\mathrm{p}<0.001), 2.3 \mathrm{~kg}$ higher leg lean mass

$155(\mathrm{p}<0.001)$ and $27 \%$ higher $\mathrm{VO}_{2 \max }(\mathrm{p}<0.001$, Table 1). Compared to EC, EH showed $16 \%$ lower total

156 body fat percentage $(\mathrm{p}<0.001), 22 \%$ lower android fat percentage $(\mathrm{p}=0.002), 14 \%$ lower gynoid fat

157 percentage $(\mathrm{p}<0.001), 3.6 \mathrm{~kg}$ higher total lean mass $(\mathrm{p}<0.001), 1.2 \mathrm{~kg}$ higher leg lean mass $(\mathrm{p}=0.005)$

158 and $31 \%$ higher $\mathrm{VO}_{2 \max }(\mathrm{p}<0.001$, Table 1$)$. Total lean mass was even $3.0 \mathrm{~kg}$ higher in $\mathrm{EH}$ compared

159 to young controls (YC) $(\mathrm{p}=0.011)$.

160

Table 1. Group characteristics in young football players (YF), young controls (YC), elderly team handball players (EH) and elderly controls (EC).

\begin{tabular}{|c|c|c|c|c|c|c|c|c|c|c|c|c|c|c|c|c|}
\hline \multirow[b]{2}{*}{ Age (yrs) } & \multicolumn{3}{|c|}{$\mathbf{Y F}(n=29)$} & \multicolumn{5}{|c|}{$\mathbf{Y C}(n=30)$} & \multicolumn{3}{|c|}{$\mathbf{E H}(n=35)$} & \multicolumn{5}{|c|}{$\mathbf{E C}(n=35)$} \\
\hline & 22.5 & \pm & 0.6 & & 24.9 & \pm & 0.4 & $\S \S$ & 63.9 & \pm & 0.7 & & 66.1 & \pm & 0.6 & $\dagger$ \\
\hline \multicolumn{17}{|l|}{ Exercise/fitness } \\
\hline All exercise (hrs/wk) & 9.0 & \pm & 0.4 & \#\#\# & 0.1 & \pm & 0.0 & & 4.7 & \pm & 0.5 & $* * *$ & 0.2 & \pm & 0.1 & \\
\hline Team handball/football (hrs/wk) & 6.7 & \pm & 0.2 & & - & \pm & - & & 2.0 & \pm & 0.1 & & - & \pm & - & \\
\hline $\mathrm{VO}_{2 \max }(\mathrm{ml} / \mathrm{min} / \mathrm{kg})$ & 45.3 & \pm & 1.0 & \#\#\# & 35.7 & \pm & 0.9 & & 30.2 & \pm & 1.2 & $* * *$ & 23.1 & \pm & 0.8 & \\
\hline \multicolumn{17}{|l|}{ Body composition } \\
\hline Body mass (kg) & 65.8 & \pm & 1.6 & & 64.3 & \pm & 2.3 & & 69.2 & \pm & 1.5 & & 70.5 & \pm & 1.9 & \\
\hline Total body fat (\%) & 26.3 & \pm & 0.8 & & 33.5 & \pm & 1.1 & $\S \S \S$ & 34.4 & \pm & 1.4 & & 41.1 & \pm & 1.0 & $\dagger+\dagger$ \\
\hline Android fat (\%) & 20.8 & \pm & 1.2 & & 30.6 & \pm & 2.0 & $\S \S \S$ & 34.6 & \pm & 2.3 & & 44.1 & \pm & 1.8 & $\dagger \dagger$ \\
\hline Gynoid fat (\%) & 30.7 & \pm & 0.9 & & 38.3 & \pm & 0.9 & $\S \S \S$ & 37.2 & \pm & 1.2 & & 43.3 & \pm & 0.8 & $+1+$ \\
\hline $\mathrm{A} / \mathrm{G}$ ratio & 0.7 & \pm & 0.0 & & 0.8 & \pm & 0.0 & $\S$ & 0.9 & \pm & 0.0 & & 1.0 & \pm & 0.0 & \\
\hline Total lean mass $(\mathrm{kg})$ & 46.3 & \pm & 0.9 & \#\#\# & 40.5 & \pm & 1.0 & & 43.4 & \pm & 0.6 & $* * *$ & 39.8 & \pm & 0.7 & \\
\hline Leg lean mass (kg) & 16.7 & \pm & 0.4 & \#\#\# & 14.4 & \pm & 0.4 & & 15.0 & \pm & 0.3 & $* *$ & 13.8 & \pm & 0.3 & \\
\hline \multicolumn{17}{|l|}{ Telomere length (kb) } \\
\hline MNC & 5.12 & \pm & \#\# & $\#$ & 4.21 & \pm & \#\# & & 3.16 & \pm & \#\# & & 3.08 & \pm & \#\# & \\
\hline Lymphocytes & 5.67 & \pm & \#\# & $\#$ & 4.59 & \pm & \#\# & & 3.40 & \pm & \#\# & & 3.25 & \pm & \#\# & \\
\hline Monocytes & 4.47 & \pm & \#\# & & 4.25 & \pm & \#\# & & 3.16 & \pm & & & 2.91 & \pm & \#\# & \\
\hline \multicolumn{17}{|l|}{ mtDNA copy number } \\
\hline MNC & 962 & \pm & 49 & $\#$ & 801 & \pm & 38 & & 976 & \pm & 51 & & 1061 & \pm & 56 & \\
\hline Lymphocytes & 853 & \pm & 39 & $\#$ & 715 & \pm & 36 & & 891 & \pm & 48 & & 1032 & \pm & 65 & $\dagger$ \\
\hline Monocytes & 386 & \pm & 22 & & 399 & \pm & 21 & & 468 & \pm & 22 & & 439 & \pm & 19 & \\
\hline
\end{tabular}

Group means \pm SEM. \#p<0.05, \#\#\#p<0.001, higher than YC; $\S p<0.05, \S \S p<0.01, \S \S \S p<0.001$, higher than $Y F ; * * p<0.01$, $* * * \mathrm{p}<0.001$, higher than $\mathrm{EC} ; \dagger \mathrm{p}<0.05, \dagger \dagger \mathrm{p}<0.01, \dagger \dagger \mathrm{p}<0.001$ higher than EH. A/G ratio, android/gynoid fat ratio; MNC, mononuclear cells; VO2max, maximal oxygen consumption. 


\section{Correlations between cellular aging markers, exercise variables and body composition}

Spearman's correlations were made for all variables. Overall, the total amount of weekly exercise and $\mathrm{VO}_{2 \max }$ were positively correlated with telomere length and mitochondrial function in all cell types (all p<0.05, Fig. 3A, Suppl. Table 4). By contrast, body fat percentage and fat distribution were negatively correlated with telomere length and mitochondrial function (all $\mathrm{p}<0.05$, Fig $3 \mathrm{~A}, \mathrm{~B}$ ). The mitochondrial function was negatively correlated with the mtDNA copy number, with some diversity according to the specific cell type (Fig. 3A, B). A positive correlation between PGC-1 $\alpha$ and PGC-1 $\beta$ expression as well as an indication of a positive correlation between telomere length and mitochondrial function was found (Fig. 3A, B). Analysing the two exercise groups combined, the weekly amount of team handball and football training was found to be positively correlated with telomere length and mitochondrial function in all cell types (all p<0.05, Fig. 3B, Suppl. Table 5). In the exercise groups, total lean mass was positively correlated with telomere length in lymphocytes and MNCs (both p<0.05, Fig. 3B).
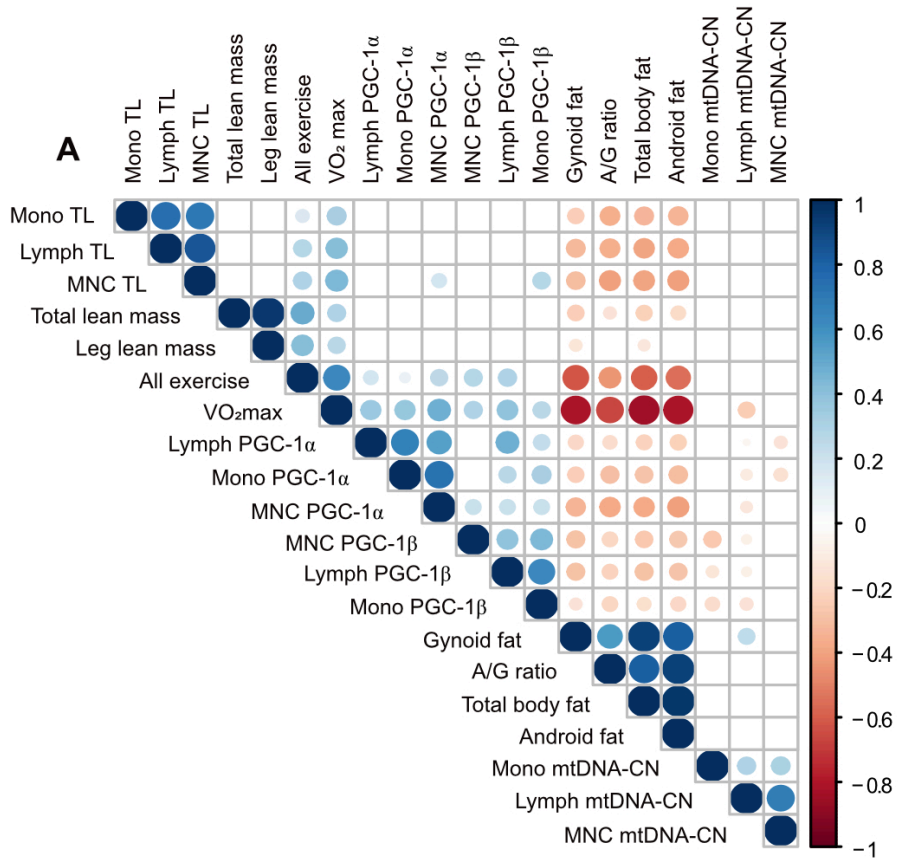

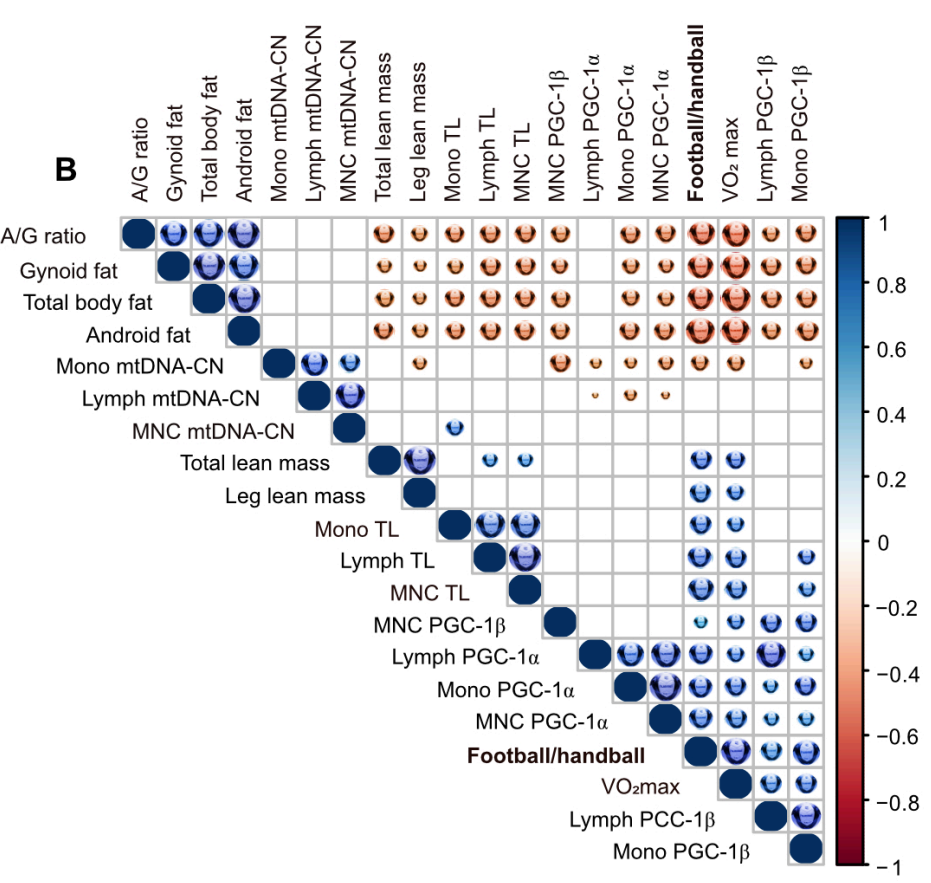

Figure 3. Spearman's correlations between the investigated variables visualised as arc diagrams in all participants (A) and in football/team handball players only (B). A/G ratio, android/gynoid fat ratio; All exercise, hours of weekly exercise 
of all types; Football/handball, hours of weekly football or team handball training; Lymph, lymphocytes; MNC, mononuclear cells; Mono, monocytes; mtDNA-CN, mitochondrial copy number; TL, telomere length; $\mathrm{VO}_{2 \max }$, maximal oxygen consumption.

\section{DISCUSSION}

This cross-sectional study is the first to investigate the effect of football and team handball training on telomere length and mitochondria in women. Furthermore, inclusion in the same study of two essential hallmarks of aging is quite unique and may lead to a broader understanding of the potential anti-aging effects of regular exercise. The main findings were that: 1) young elite football players (YF) had longer telomeres in both lymphocytes (24\%) and MNCs (22\%) compared to untrained young controls (YC) as well as a higher mtDNA copy number in lymphocytes (19\%) and MNCs (20\%) compared to YC; and 2) lifelong trained elderly team handball players (EH) had a lower mtDNA copy number in lymphocytes (14\%) compared to untrained elderly controls (EC), but higher mitochondrial function in lymphocytes (3.4-fold higher PGC-1 $\alpha$ expression) compared to EC. Mitochondrial function in MNCs was also higher ( 1.5-fold) in EH compared to EC according to the univariate analysis.

to establish the biological age of an individual, but also to estimate the risk of age-related diseases (4). Telomere attrition is a consequence of normal aging in humans, and it has been established that telomeres gradually shorten with age as a result of the end-replication problem, albeit large intraindividual variation exists (2). The present study showed that young women on average had 1.55 $\mathrm{kb}$ longer telomeres compared to elderly women, which is comparable to differences in telomere length of $1.35 \mathrm{~kb}$ previously found between young (18-32 yrs) and older (55-72 yrs) sedentary adults of both sexes (20). With an age difference of 41.4 years between the young and elderly groups in the 
present study, this difference in telomere length corresponds to a loss of $\sim 37$ bp per year of chronological age.

Our finding of reduced telomere shortening in young, but not elderly, ball players contradicts previous observations showing an effect of exercise on telomere length in adults above 50 years only. Surprisingly, the $22-24 \%$ longer telomeres demonstrated in YF is comparable to beneficial adaptations observed in middle-aged or older athletes. Indeed, experienced ultra-distance runners aged $\sim 45$ yrs have shown $25 \%$ longer telomeres than sedentary peers $(21)$, while older (>65 yrs) endurance-trained adults have shown $22 \%$ longer telomere length compared with older people with medium activity levels (22). Despite sports participation at elite level and large exercise volumes, changes in telomere length have usually not been detected in young well-trained endurance athletes $(20,21,23)$, nor in young male elite football players (24). The inconsistency in observations between young and older adults are most likely explained by the postulation that telomere length and attrition are relatively stable from childhood to adulthood (11). Thus, the observed findings in YF are quite striking due to the young age of the group ( $22 \mathrm{yrs})$. So far, intervention studies regarding exercise and telomere shortening are sparse. While some studies have not been able to detect changes in telomere length following short-term exercise interventions $(25,26)$, a few studies have observed minor adaptations of $2-4 \%(12,27)$. Hence, the $22-24 \%$ superior telomere length observed in YF was assumed to be a result of many years of regular exercise, here among elite football training. To the best of our knowledge, the effect of football training on telomere shortening has never been investigated. Our findings show that football training at elite level might be particularly effective for achieving cellular anti-aging adaptations in young women.

Our correlation analysis showed that $\mathrm{VO}_{2 \max }$ and the weekly amount of exercise were positively correlated with telomere length. An association between better cardiorespiratory fitness or 
a large training load and longer telomeres was found in $80 \%$ of all studies included in a recent systematic review (10). The association was, however, mainly observed in middle-aged and older people, presumably due to the limited telomere attrition in young age. By contrast, at least two studies have found an inverted "U" correlation, showing that both low and very high physical activity are associated with increased telomere shortening $(28,29)$. Thus, there may be an upper limit of exercise volume, where too much exercise elicits a negative effect on cellular aging. In the present study, 7 hours of weekly football training had a positive effect on telomere length, indicating that this amount of football training is not excessive. Total lean mass was also positively correlated with telomere length in the two exercise groups, indicating that the anabolic effect of exercise training may be an important factor for telomere adaptations.

As EH demonstrated considerably higher $\mathrm{VO}_{2 \max }$ and exercise volume than $\mathrm{EC}$, it was slightly surprising that the telomere length did not differ between the groups. However, the intragroup variation in $\mathrm{EH}$ in $\mathrm{VO}_{2 \max }(18-45 \mathrm{ml} / \mathrm{min} / \mathrm{kg})$ and exercise volume (1.5-12 hrs/wk) was quite large. It is plausible that the average exercise volume or intensity, which are responsible for $\mathrm{VO}_{2 \max }$, were not adequate in EH to elicit detectable changes in telomere shortening. Another decisive factor may be the sex and age of the group. It has been demonstrated that the oestrogen level is positively associated with telomere length, possibly due to the ability of the hormone to upregulate telomerase and concurrently reduce oxidative stress (30). As EH consisted of postmenopausal women, their oestrogen level was expected to be negligible, and they may not have the capacity to upregulate telomerase activity to the same extent as young women. Although telomere length did not significantly differ between the two elderly groups, the absolute values were 3-8\% higher in EH compared to EC depending on the cell type. In a recent male football study by Hagman et al. (24), differences in telomere length of only $1.3-2.5 \%$ were found to be statistically significant using the fluorescence in situ hybridisation coupled with flow cytometry (Flow-FISH) technique, but not with 
the qPCR method. Previous validation studies have confirmed that Flow-FISH may be more sensitive when measuring telomere length (31), and we speculate whether use of this technique or a larger sample size would have resulted in significant findings in EH. It is, however, possible that football training is superior to team handball training regarding achievement of telomere adaptations, but further studies are necessary to address this.

Mitochondria are characterised as 'powerhouses of the cell', as their primary role is to supply ATP from aerobic respiration for growth, development and preservation of the cell (13). However, mitochondria also play a central role in the aging process through their vital functions for cell survival, including inflammation, ROS production, senescence and apoptosis. In the present study, we found a higher mtDNA copy number in elderly women compared to young. This agerelated increase appeared to be a consequence of, and compensatory mechanism for, the observed decline in mitochondrial function in the elderly participants, as mitochondrial function was negatively correlated with mtDNA copy number. Mitochondrial function was evaluated based on PGC-1 $\alpha$ and PGC-1 $1 \beta$ expression. While PGC- $1 \alpha$ is often referred to as the 'master regulator' of mitochondrial biogenesis (32) and mediates adaptations in tissues with high-energy needs, PGC-1 $\beta$ is mainly believed to participate in the maintenance of basal mitochondrial function (33).

While few studies have investigated mitochondria in male football players $(34,35)$, mitochondrial content and function has, to the best of our knowledge, never been studied in female elite football players. Furthermore, this is the first study to examine the effects of team handball training on mitochondria. In the present study, YF showed a 19-20\% higher mtDNA copy number compared to YC. Meanwhile, EH showed a 14\% lower lymphocyte mtDNA copy number compared to EC, but 3.4-fold higher mitochondrial function in lymphocytes. Interestingly, the mtDNA copy 
number was comparable in the two exercise groups despite the large age difference, while the two non-exercise groups showed fluctuations in mtDNA copy number. A similar mitochondrial function observed in the two young groups was most likely explained by the markedly higher mtDNA copy number in YF. Our results show that an upregulation of the mitochondrial content, and not function, was favoured in young athletes, potentially due to sufficiently high mitochondrial function in young age.

Mitochondria are highly plastic organelles that can be remodelled in several ways according to the energetic challenges of the cell. These processes can be triggered by acute and/or chronic physical activity, and mitochondrial adaptations are generally expected following aerobic exercise training (13). Previous studies indicate that the type of exercise training is decisive for the specific and diverse mitochondrial adaptations (32). Indeed, a recent review concluded that training volume is crucial for changes in mitochondrial content, while exercise intensity appears to be important for changes in mitochondrial function (36). Football and team handball training are both characterised as intermittent high-intensity exercise $(16,17)$. Although the exercise intensity during team handball training has never been investigated in elderly women, Hornstrup et al. (37) have previously shown that the average heart rate during team handball training is very high $(\sim 85 \%$ of $\mathrm{HR}_{\max }$ ) and independent of prior team handball experience. Thus, sufficiently high exercise intensities necessary for changes in mitochondrial function were anticipated in both YF and EH. Increased PGC$1 \alpha$ expression has previously been observed in lifelong trained male football players (35) and in untrained men following long-term recreational football training (34), indicating that football training can improve mitochondrial function in some cases.

The effect of chronic exercise on mitochondrial function is believed to be a cumulative result of repeated bouts of acute exercise, as the expression of PGC- $1 \alpha$ has been shown to be markedly increased by a single session of aerobic exercise $(32,38)$. Thus, the superior mitochondrial function 
observed in $\mathrm{EH}$ was expected to be a cumulative effect of many years of regular team handball training. Although acute changes in PGC- $1 \alpha$ and PGC-1 $\beta$ expression have been shown to differ following exercise, a positive correlation between transcription of the two genes has been found (38). This is in line with the results from the present study showing positive correlations between PGC-1 $\alpha$ and PGC-1 $\beta$ expression, but more significant between-group differences in PGC-1 $\alpha$ expression.

Some studies have suggested that $\mathrm{VO}_{2 \max }$ and aerobic capacity are not only limited by cardiorespiratory factors, but also by the mitochondria $(32,36)$. In line with this theory, our correlation analyses showed that $\mathrm{VO}_{2 \max }$ was positively correlated with mitochondrial function. A positive association between PGC- $1 \alpha$ expression and $\mathrm{VO}_{2 \max }$ has also previously been found in lifelong trained male football players (35). Due to the noticeably higher $\mathrm{VO}_{2 m a x}$ in $\mathrm{YF}$ compared to $\mathrm{YC}$, higher mitochondrial function was expected in $\mathrm{YF}$. However, $\mathrm{VO}_{2 \max }$ varied a lot within $\mathrm{YF}$ (33$55 \mathrm{ml} / \mathrm{min} / \mathrm{kg}$ ) and was markedly lower compared to other young female top athletes, e.g. middledistance runners with $\mathrm{VO}_{2 \max }$ values of $\sim 55 \mathrm{ml} / \mathrm{min} / \mathrm{kg}$ (39). It could be speculated that a lower variation within $\mathrm{YF}$, or a specific lower limit regarding $\mathrm{VO}_{2 \max }$, would have affected our findings. Our correlation analyses also showed that body fat percentage and fat distribution were negatively correlated with both mitochondrial function and telomere length, which is in line with previous findings in women $(30,31)$. The demonstrated correlations emphasise the importance of preserving reasonable physical fitness $\left(\mathrm{VO}_{2 \max }\right)$ and lean body mass through regular participation in aerobic exercise, while avoiding too much body fat, to achieve healthy aging.

Several hallmarks of aging have been identified (2), but neither of the aging theories appear to be fully satisfactory, and the complex interconnections are still a major challenge in aging research. Telomere length and mitochondrial function both exhibit a profound impact on the aging process, and pathological dysfunction in either has been proven to accelerate aging (2). Thus, a direct 
association between telomere shortening and mitochondrial dysfunction has been proposed. During repetitive cell division, the absence or insufficient activity of telomerase results in telomere attrition, loss of chromosome 'capping' function and activation of p53 (7). In general, p53 is postulated to mediate growth arrest, senescence and apoptosis in tissues with a high turnover. p53 has, however, also been shown to decrease mitochondrial function through binding and suppression of PGC-1 $\alpha$ and PGC-1 $\beta$ and their downstream gene network (8). This telomere-p53-PGC axis is argued to compromise metabolism and organ function and contribute to development of age-related disorders. An indication of a correlation between telomeres and mitochondria was observed in the present study. Indeed, telomere length was positively correlated with PGC- $1 \alpha$ and PGC- $1 \beta$ expression as wells as mtDNA copy number in some cell types. Existence of a telomere-mitochondria interplay in leukocytes has previously been found in different groups of participants (40), and a co-regulation due to oxidative stress, inflammation and repeated cell replication is possible $(5,40)$. It might be speculated that the beneficial effects of football and team handball training in the present study were a result of reduced oxidative stress and inflammation, but more studies are required to establish this. Cellular senescence and cell death are other central hallmarks of aging associated with telomere shortening and mitochondrial dysfunction (2). Due to a weaken immune system in old age, senescent cells are accumulated in all types of body tissue. This accumulation reduces tissue repair and increases chronic inflammation, which affects the progression of aging and increases the risk of age-related diseases (41). Hence, telomere shortening and mitochondrial dysfunction are linked to the onset and progression of many of the same age-related diseases, such as cardiovascular and neurodegenerative diseases as well as metabolic disorders like type 2 diabetes $(5,42)$. PGC-1 $\alpha$ seems to play a key role in endothelial cell regulation and atherosclerosis, as an upregulation of the gene has been shown to prevent development of, or even reduce, atherosclerotic lesions (43). Thus, the finding of higher mitochondrial function in EH may indicate a significant reduced risk of CVD. Furthermore, 
numerous studies have shown that mitochondrial dysfunction is associated with muscle wasting in different muscular disorders, and that elevated PGC-1 $\alpha$ levels may postpone the onset and reduce the progression of age-related loss of muscle mass (42). EH demonstrated an impressive total lean mass that was $3 \mathrm{~kg}$ higher than observed in YC despite an age difference of more than $40 \mathrm{yrs}$. It is possible that the upregulated PGC-1 $\alpha$ expression in $\mathrm{EH}$ was linked to muscle mass maintenance in the group despite the high age.

Finally, possessing short telomeres is associated with a mortality rate that is almost

twice as high as in those having longer telomeres (4). Interestingly, telomere length may predict mortality risk in young individuals in particular, as the mortality association diminishes with age (44).

Hence, the noticeably longer telomeres in YF may result in a markedly reduced mortality risk.

Whether telomere attrition and mitochondrial dysfunction are causative or secondary effects of the diseases are not fully established, and more research within this aging topic is needed. be ruled out. It is plausible that the exercise groups in general have a healthier lifestyle than the sedentary groups, which most likely poses an additive effect of the sports participation itself on the measured aging markers. Indeed, telomere length is influenced by several other factors, such as dietary and smoking habits, perceived stress levels, socioeconomic status, chronic inflammation and paternal age (4). To exclude the effects of confounding factors and natural genetics, a large randomised controlled trial is needed. As oestrogen is assumed to play a role in telomere regulation, measurement of circulating oestradiol and inclusion of this in the correlation analysis could have been interesting. Although the effect of both team handball and football training was investigated in the present study, a direct comparison of the two exercise types was not attempted. Similar team sports, 
such as basketball or floorball, may have a comparable effect on aging, although this has not yet been investigated.

In summary, this cross-sectional study showed that elite football and lifelong team handball training are associated with beneficial anti-aging cellular effects in MNCs in women. Specifically, young elite football players demonstrated higher telomere length and higher mtDNA copy number compared to young untrained controls, while elderly team handball players showed higher mitochondrial function compared to elderly untrained controls. These cellular adaptations were positively correlated with both $\mathrm{VO}_{2 \max }$ and the amount of weekly exercise, emphasising the importance of preserving a reasonable fitness and activity level irrespective of age. As telomere shortening and mitochondrial dysfunction are highly associated with several age-related diseases and mortality, our findings indicate that women engaged in team sports such as football and team handball may potentially increase their health span and, ultimately, lifespan.

\section{METHODS}

\section{Participants}

This study comprised a relatively large sample size of 129 healthy (no chronic diseases) and nonsmoking (>1 yr) women. During the recruiting process, a total of 290 women were screened for participation, of whom 161 were excluded due to lack of compliance with the inclusion criteria $(n=84)$ or because they declined to participate after consideration $(n=77)$. The included participants were

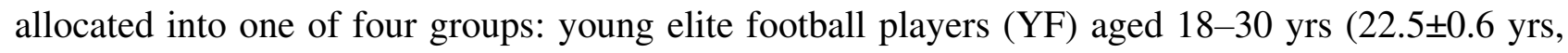
$n=29)$; untrained young controls (YC) aged 18-30 yrs (24.9 \pm 0.4 yrs, $n=30)$; lifelong trained elderly team handball players $(\mathrm{EH})$ aged $60-80 \mathrm{yrs}(63.9 \pm 0.7 \mathrm{yrs}, n=35)$; and untrained elderly controls (EC) aged 60-80 yrs $(66.1 \pm 0.6 \mathrm{yrs}, n=35)$. EH were recruited from team handball clubs all over Denmark 
with help from the Danish Handball Federation (Dansk Håndbold Forbund, DHF), whereas YF were recruited from football teams in Zealand, Denmark, competing in one of the two best female leagues in Denmark (3F League or $1^{\text {st }}$ Division). The age-matched untrained controls were recruited through local newspapers, local institutions and online advertisements.

YF had a history of $14.9 \pm 0.6$ yrs of regular football training and had been playing at a high level for $6.2 \pm 0.6$ yrs. On average, their age of debut was $6.9 \pm 0.5$ yrs. YF had a total of $6.7 \pm 0.2$ hours of football training per week, including 1.0 \pm 0.090 -min matches, plus $2.3 \pm 0.4$ hours of other types of training per week, primarily resistance training and running. Including all types of exercise, YF had been regularly physically active for $17.7 \pm 0.7$ yrs at the time of the study. EH had a history of $43.3 \pm 2.0 \mathrm{yrs}$ of regular team handball training and their age of debut was $12.1 \pm 1.4 \mathrm{yrs}$. At the time of the study, EF had a total of $2.0 \pm 0.1$ hours of team handball training per week, including $0.6 \pm 0.1$ 50-min matches. Besides team handball training, EH had 2.7 \pm 0.4 hours of other types of training per week, e.g. jogging, resistance training, cycling, yoga, swimming, dancing and gymnastics. Including all types of exercise, EH had been regularly physically active for $50.2 \pm 1.6$ yrs. YC and EC had not participated in regular physical exercise for $4.8 \pm 0.9$ and $14.7 \pm 3.2 \mathrm{yrs}$, respectively, or had never participated in a regular exercise programme ( $n=10$ in EC). Furthermore, the untrained controls had never engaged in sport at a high level.

Among the young women, the use of hormonal contraception included birth control pills ( $n=15$ in YF, $n=12$ in YC) and an intrauterine device ( $n=2$ in YF, $n=3$ in YC). None of the elderly women took hormone supplements due to menopause, but some used blood-pressure-lowering ( $n=2$ in $\mathrm{EH}, n=9$ in EC) or cholesterol-lowering ( $n=2$ in $\mathrm{EH}, n=6$ in EC) medication due to mild-tomoderate hypertension or hyperlipidaemia. None of the participants had been exposed to chemotherapy or radiation therapy. All subjects provided written informed consent. The study was 
carried out in accordance with the Declaration of Helsinki and approved by the local ethical committee of the Capital Region of Denmark (journal. no. H-15009312).

\section{Clinical testing}

All clinical testing was carried out in the morning after an overnight fast ( $>8$ hours). The effect of the menstrual cycle and associated hormonal fluctuations in the young women was considered carefully by consistent sampling of the blood within a narrow timespan according to each participant's individual menstrual cycle (days 3-9). The participants were not allowed to perform any strenuous exercise for 48 hours prior to testing to exclude acute effects. A peripheral venous blood sample was collected in resting state and under standardised conditions. $60 \mathrm{ml}$ of sodium citrate blood was used for isolation of mononuclear cells (MNCs), as described below. Prior to blood sampling, whole-body dual-energy X-ray absorptiometry (DXA) was performed to evaluate body fat percentage, fat distribution and lean body mass. The effective radiation dose for the DXA scan was $4.66 \mu \mathrm{Sv}$, and all analyses were performed using enCORE Version 14.10 software (GE Healthcare). On a separate test day ( $>48$ hours from the first test day), maximal oxygen consumption $\left(\mathrm{VO}_{2 m a x}\right)$ was measured during a maximal fitness test on an ergometer bike using a computerised metabolic measurement system (Oxycon Pro ${ }^{\circledR}$ ). The young participants completed two submaximal loads (40 and 80W) of 3 minutes each, after which the load was increased by $15 \mathrm{~W}$ every $30 \mathrm{~s}$. The elderly participants only completed the lowest submaximal load (40W) for 3 minutes, after which the load was increased by $10 \mathrm{~W}$ every $30 \mathrm{~s}$. All participants biked until exhaustion, and $\mathrm{VO}_{2 \max }$ was calculated as the mean over $30 \mathrm{~s}$ when oxygen consumption peaked.

\section{Isolation of MNCs}


Ficoll density gradient centrifugation was performed to isolate MNCs from $60 \mathrm{ml}$ of sodium citrate blood, as previously described (23), and the cell number was quantified in a Neubauer chamber after staining with Türk's solution. Immediately after isolation, the MNCs were resuspended in a freezing medium (RPMI1640 medium $+10 \%$ foetal calf serum $+5 \%$ dimethyl sulfoxide), distributed into cryotubes and gently frozen to $-80^{\circ} \mathrm{C}$ in a "Mr. Frosty" freezing container (Thermo Fisher Scientific, Braunschweig, Germany). The deep-frozen cryotubes were transported on dry ice to Dr Asghar's lab at Karolinska Institutet in Solna (Stockholm, Sweden) and kept at $-80^{\circ} \mathrm{C}$ until analysis.

\section{DNA and RNA isolation}

Lymphocytes and monocytes were separated using the MACS cell sorting protocol (see supplementary method for details). DNA was extracted from sorted cells using a Qiagen kit (QIAamp ${ }^{\circledR}$ DNA Blood Mini Kit, cat \# 52304) according to the manufacturer's instructions. DNA was quantified using a Qubit 1x DSDNA HS kit (cat \# Q33231, Invitogen) on Qubit and diluted to 1 $\mathrm{ng} / \mathrm{ul}$ for the telomere and mtDNA copy number measurement. RNA was extracted from sorted cells using a Qiagen kit (QIAamp ${ }^{\circledR}$ RNA Blood Mini Kit, cat \# 990395) according to the manufacturer's instructions. RNA was then quantified using a Qubit ${ }^{\mathrm{TM}}$ RNA HS kit (cat \# Q32855, Invitrogen) on Qubit.

\section{Telomere and mtDNA copy number essay}

Telomere length and mtDNA copy number were measured using a ScienCell kit (cat \# 8958). Each 15 ul reaction contained 7.5ul QuantiNova Syber green (cat \# 208054, Qiagen), 0.5 ul telomere or single-copy (SCR) or mitochondrial primers, 0.1 ul ROX (passive reference dye), 1.9 ul DNA/RNA free water and $5 \mathrm{ul}(1 \mathrm{ng} / \mathrm{ul})$ template DNA. For telomere quantitative polymerase chain reaction (qPCR), the thermal cycle profile comprised incubation at $50^{\circ} \mathrm{C}$ for $2 \mathrm{~min}$ and $95^{\circ} \mathrm{C}$ for $10 \mathrm{~min}$ before 
running 30 thermal cycles $\left(95^{\circ} \mathrm{C}\right.$ for $15 \mathrm{~s}, 56^{\circ} \mathrm{C}$ for $45 \mathrm{~s}$ and $72^{\circ} \mathrm{C}$ for $\left.45 \mathrm{~s}\right)$. For single-copy gene and mtDNA copy number qPCR, the thermal cycle profile comprised incubation at $50^{\circ} \mathrm{C}$ for 2 min and $95^{\circ} \mathrm{C}$ for $10 \mathrm{~min}$ before running 40 thermal cycles $\left(95^{\circ} \mathrm{C}\right.$ for $15 \mathrm{~s}, 54^{\circ} \mathrm{C}$ for $45 \mathrm{~s}$ and $72^{\circ} \mathrm{C}$ for $\left.45 \mathrm{~s}\right)$. Each assay was run on separate plates and each plate contained a serially diluted DNA sample to calculate PCR efficiency. The PCR acceptance value was set as $100 \pm 15 \%$, and any plate producing the PCR efficiency outside this range was rerun. Each sample was run in triplicate, and mean $C_{T}$ value was used for final calculation after carefully checking the melt curve for each sample. A reference genomic DNA was added on each plate with known telomere length $(369 \pm \mathrm{kb})$ and mtDNA copy number (1200 $\pm \mathrm{x}$ copies). $\Delta C_{T}$ for both telomere length and mtDNA copy number was calculated using the formula ( $C_{T}$ target sample - $C_{T}$ reference sample) after adjusting PCR efficiency using the Pfaffl method (45). We then calculated $\Delta \Delta C_{T}$ for both telomere length and mtDNA copy number using the formula (TEL $\Delta C_{T}-\mathrm{SCR} \Delta C_{T}$ or $\operatorname{mtDNA} \Delta C_{T}-\mathrm{SCR} \Delta C_{T}$ ). Relative telomere of target sample to reference sample was calculated by $2^{\wedge}-\Delta \Delta C_{T}$, and the ratio was then multiplied by $369 \mathrm{~Kb}$ to get telomere length per diploid cell. Telomere length of diploid cell was divided by the number of chromosome ends (92) to get average telomere length at each chromosome end $\left(2^{\wedge}-\Delta \Delta C_{T} \times 369 / 92\right)$. mtDNA copy number per diploid cell of target sample to reference sample was calculated by $2^{\wedge}$ $\Delta \Delta C_{T}$, and the ratio was then multiplied by 1200 mtDNA copy number for each sample $\left(2^{\wedge}-\Delta \Delta C_{T} \mathrm{x}\right.$ 1200). Our method showed very high repeatability for telomere length (ICC $=97)$ and mtDNA copy number $(\mathrm{ICC}=98)$.

\section{Gene expression}

cDNA was synthesised using a QuantiTec Reverse Transcriptase kit (cat \# 205311) according to the manufacturer's instructions. The plate was incubated for 10 minutes at $25^{\circ} \mathrm{C}$ followed by 1 hour at $42^{\circ} \mathrm{C}$ and 5 minutes at $85^{\circ} \mathrm{C}$ to inactivate the enzyme on a QuantStudio5 thermocycler. Relative gene 
expression of peroxisome proliferator-activated receptor gamma coactivator 1 -alpha (PGC-1 $\alpha)$ and beta (PGC-1 $\beta$ ) was determined using the comparative $\Delta C_{T}$ method by calculating the $C_{T}$ values of the target genes (PGC-1 $\alpha$ and PGC-1 $\beta$ ) against the $C_{T}$ values of the reference gene (GAPDH). Both target gene and GAPDH were run in triplicate, amplified in same wells, and respective $C_{T}$ values were averaged before performing the $\Delta C_{T}$ calculation $\left(\Delta C_{T}=C_{T}\right.$ Target $-C_{T}$ GAPDH $)$. Gene expression values were converted into $\log 2$ of $\Delta C_{T}\left(2^{\wedge}-\Delta C_{T}\right)$.

\section{Mitochondrial function}

PGC-1 $\alpha$ and PGC-1 $\beta$ expression was measured using a TaqMan ${ }^{\circledR}$ Gene Expression Assay (cat \# Hs00173304_m1, Hs00993805_m1; Applied Biosystem) on a QuantStudio 5 qPCR instrument. The total qPCR reaction of $20 \mu \mathrm{l}$ contained $3 \mu \mathrm{l}$ cDNA, $10 \mu \mathrm{l}$ TaqMan ${ }^{\circledR}$ Multiplex Master Mix (cat \#

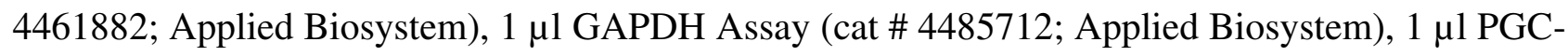
$1 \alpha$ and PGC-1 $\beta$ Assay and ddH2O. The TaqMan ${ }^{\circledR}$ GAPDH Assay was added to each run as an endogenous control. The thermal profile comprised $95^{\circ} \mathrm{C}$ for $20 \mathrm{~s}$, followed by 45 thermal cycles $\left(95^{\circ} \mathrm{C}\right.$ for $1 \mathrm{~s}$ and $60^{\circ} \mathrm{C}$ for $\left.20 \mathrm{~s}\right)$.

\section{Statistical analysis}

Statistical analyses were performed in Stata (version 16), and figures were generated using JMP (version 14). Univariate and multivariate analyses were used to assess the differences between the groups for all the studied variables. Age was included in all multivariate models as a covariate. We used the mathematical and topological features of Spearman's correlation $\left(\mathrm{r}_{\mathrm{s}}\right)$ and visualised it as arc diagrams using R-studio (Version 1.1.442) to investigate the potential correlation between variables. In the event of missing values in the dataset, these were imputed $(<5 \%)$ to complete the data set. The 
results remained the same with or without imputed values. Results are presented as means \pm SEM and the statistical significance level was set at $\mathrm{p}<0.05$.

\section{ACKLNOWLEDGEMENTS}

The present study was funded by the Department of Sports Science and Clinical Biomechanics, SDU Sport and Health Sciences Cluster, University of Southern Denmark, Denmark, and The Novo Nordisk Foundation grant to Team Danmark granted to PK, as well as the Swedish Research Council (2018-02266) and Ragnar Söderberg Foundation (M13/18) through grants to MA. Cellular analyses were conducted at Dr Asghar's lab at the Division of Infectious Diseases, Department of Medicine, Solna, Karolinska Institutet, Sweden. First and foremost, we would like to thank the participants for their crucial participation, as well as the Danish Handball Federation (Dansk Håndbold Forbund, DHF) and the dedicated football coaches for their assistance with recruiting the team handball and football players. A special thank you to Jon Egelund, Jørn Wulff Helge, Thomas Morville, Jens Jung Nielsen and Jonas Mengel-From for their technical collaboration and scientific advice.

\section{AUTHOR CONTRIBUTIONS}

MH, PK and MA conceived the study design and applied for funding. MH recruited participants, carried out data collection and analysis, interpreted the study results and drafted the manuscript. BF carried out data collection, while RM carried out data analysis, and both edited the manuscript. MA carried out data analysis, interpreted the study results and drafted the manuscript. PK interpreted the study results and edited the manuscript. All authors have approved the final version of the manuscript and agree with the order of presentation of authors.

\section{COMPETING INTERESTS}


The authors declare no competing interests.

535

536

\section{DATA AVAILABILITY STATEMENT}

537

Data available on request from Muhammad Asghar (asghar.muhammad@ki.se) and/or Marie

538 Hagman (mhagman@health.sdu.dk).

539

\section{REFERENCES}

541 1. Christensen K, Doblhammer G, Rau R, Vaupel JW. Ageing populations: the challenges ahead. Lancet (London, England). 2009;374(9696):1196-208.

2. Lopez-Otin C, Blasco MA, Partridge L, Serrano M, Kroemer G. The hallmarks of aging. Cell. 2013;153(6):1194-217.

545 3. Rudolph KL, Chang S, Lee H-W, Blasco M, Gottlieb GJ, Greider C, et al. Longevity, Stress Response, and Cancer in Aging Telomerase-Deficient Mice. Cell. 1999;96(5):70112.

4. Herrmann M, Pusceddu I, Marz W, Herrmann W. Telomere biology and age-related diseases. Clin Chem Lab Med. 2018;56(8):1210-22.

Rizvi S, Raza ST, Mahdi F. Telomere length variations in aging and age-related diseases. Curr Aging Sci. 2014;7(3):161-7.

6. Njajou OT, Hsueh WC, Blackburn EH, Newman AB, Wu SH, Li R, et al. Association between telomere length, specific causes of death, and years of healthy life in health, aging, and body composition, a population-based cohort study. J Gerontol A Biol Sci

556 7. Sahin E, Depinho RA. Axis of ageing: telomeres, p53 and mitochondria. Nature Reviews Molecular Cell Biology. 2012;13(6):397-404. 
8. Sahin E, Colla S, Liesa M, Moslehi J, Müller FL, Guo M, et al. Telomere dysfunction 559 560 induces metabolic and mitochondrial compromise. Nature. 2011;470(7334):359-65.

9. Daskalopoulou C, Stubbs B, Kralj C, Koukounari A, Prince M, Prina AM. Physical activity and healthy ageing: A systematic review and meta-analysis of longitudinal cohort studies. Ageing research reviews. 2017;38:6-17.

10. Marques A, Gouveira ÉR, Peralta M, Martins J, Venturini J, Henriques-Neto D, et al. Cardiorespiratory fitness and telomere length: a systematic review. J Sports Sci. 2020;38(14):1690-7.

11. Oeseburg H, De Boer RA, Van Gilst WH, Van Der Harst P. Telomere biology in healthy aging and disease. Pflügers Archiv - European Journal of Physiology. 2010;459(2):25968.

12. Werner CM, Hecksteden A, Morsch A, Zundler J, Wegmann M, Kratzsch J, et al. Differential effects of endurance, interval, and resistance training on telomerase activity and telomere length in a randomized, controlled study. Eur Heart J. 2019;40(1):34-46.

13. Nilsson MI, Tarnopolsky MA. Mitochondria and Aging - The Role of Exercise as a Countermeasure. Biology. 2019;8(2):40.

14. Stenner BJ, Buckley JD, Mosewich AD. Reasons why older adults play sport: A systematic review. Journal of sport and health science. 2019.

15. Castagna C, de Sousa M, Krustrup P, Kirkendall DT. Recreational team sports: The motivational medicine. J Sport Health Sci. 2018;7(2):129-31.

16. Taylor JB, Wright AA, Dischiavi SL, Townsend MA, Marmon AR. Activity Demands During Multi-Directional Team Sports: A Systematic Review. Sports Med. 2017;47(12):2533-51. 
581 17. Krustrup P, Krustrup BR. Football is medicine: it is time for patients to play! Br J Sports Med. 2018;52(22):1412-4.

583 18. Hornstrup T, Wikman JM, Fristrup B, Póvoas S, Helge EW, Nielsen SH, et al. Fitness and health benefits of team handball training for young untrained women-A crossdisciplinary RCT on physiological adaptations and motivational aspects. Journal of sport and health science. 2018;7(2):139-48.

19. Hornstrup T, Lowenstein FT, Larsen MA, Helge EW, Povoas S, Helge JW, et al.

20. LaRocca TJ, Seals DR, Pierce GL. Leukocyte telomere length is preserved with aging in endurance exercise-trained adults and related to maximal aerobic capacity. Mech Ageing Dev. 2010;131(2):165-7. a randomized controlled trial with young adult untrained men. Eur J Appl Physiol. 2019;119(2):561-73.

21. Borghini A, Giardini G, Tonacci A, Mastorci F, Mercuri A, Mrakic-Sposta S, et al. Chronic and acute effects of endurance training on telomere length. Mutagenesis. 2015;30(5):711-6.

Osthus IB, Sgura A, Berardinelli F, Alsnes IV, Bronstad E, Rehn T, et al. Telomere length and long-term endurance exercise: does exercise training affect biological age? A pilot study. PLoS One. 2012;7(12):e52769.

23. Werner C, Furster T, Widmann T, Poss J, Roggia C, Hanhoun M, et al. Physical exercise prevents cellular senescence in circulating leukocytes and in the vessel wall. Circulation. 2009;120(24):2438-47. 
24. Hagman M, Werner C, Kamp K, Fristrup B, Hornstrup T, Meyer T, et al. Reduced telomere shortening in lifelong trained male football players compared to age-matched inactive controls. Prog Cardiovasc Dis. 2020.

25. Mason C, Risques R-A, Xiao L, Duggan CR, Imayama I, Campbell KL, et al. Independent and combined effects of dietary weight loss and exercise on leukocyte telomere length in postmenopausal women. Obesity. 2013;21(12):E549-E54.

26. Friedenreich CM, Wang Q, Ting NS, Brenner DR, Conroy SM, McIntyre JB, et al. Effect of a 12-month exercise intervention on leukocyte telomere length: Results from the ALPHA Trial. Cancer Epidemiol. 2018;56:67-74.

27. Brandao CFC, Nonino CB, De Carvalho FG, Nicoletti CF, Noronha NY, San Martin R, et al. The effects of short-term combined exercise training on telomere length in obese women: a prospective, interventional study. Sports Medicine - Open. 2020;6(1).

28. Savela S, Saijonmaa O, Strandberg TE, Koistinen P, Strandberg AY, Tilvis RS, et al. Physical activity in midlife and telomere length measured in old age. Exp Gerontol. $2013 ; 48(1): 81-4$

29. Ludlow AT, Zimmerman JB, Witkowski S, Hearn JW, Hatfield BD, Roth SM. Relationship between physical activity level, telomere length, and telomerase activity. Med Sci Sports Exerc. 2008;40(10):1764-71.

30. Shin Y-A, Lee K-Y. Low estrogen levels and obesity are associated with shorter telomere lengths in pre- and postmenopausal women. Journal of Exercise Rehabilitation. 2016;12(3):238-46.

31. Gutierrez-Rodrigues F, Santana-Lemos BA, Scheucher PS, Alves-Paiva RM, Calado RT. Direct Comparison of Flow-FISH and qPCR as Diagnostic Tests for Telomere Length Measurement in Humans. PLoS One. 2014;9(11):e113747. 
32. Huertas JR, Casuso RA, Agustín PH, Cogliati S. Stay Fit, Stay Young: Mitochondria in Movement: The Role of Exercise in the New Mitochondrial Paradigm. Oxid Med Cell Longev. 2019;2019:1-18.

33. Villena JA. New insights into PGC-1 coactivators: redefining their role in the regulation of mitochondrial function and beyond. The FEBS Journal. 2015;282(4):647-72.

34. Alfieri A, Martone D, Randers MB, Labruna G, Mancini A, Nielsen JJ, et al. Effects of long-term football training on the expression profile of genes involved in muscle oxidative metabolism. Mol Cell Probes. 2015;29(1):43-7.

35. Mancini A, Vitucci D, Labruna G, Imperlini E, Randers MB, Schmidt JF, et al. Effect of lifelong football training on the expression of muscle molecular markers involved in healthy longevity. Eur J Appl Physiol. 2017;117(4):721-30.

36. Granata C, Jamnick NA, Bishop DJ. Training-Induced Changes in Mitochondrial Content and Respiratory Function in Human Skeletal Muscle. Sports Medicine. 2018;48(8):180928.

37. Hornstrup T, Povoas S, Helge JW, Melcher PS, Fristrup B, Andersen JL, et al. Cardiovascular and metabolic health effects of team handball training in overweight women: Impact of prior experience. Scand J Med Sci Sports. 2020;30(2):281-94.

38. Wang L, Psilander N, Tonkonogi M, Ding S, Sahlin K. Similar expression of oxidative genes after interval and continuous exercise. Med Sci Sports Exerc. 2009;41(12):2136-44.

39. Oöpik V, Timpmann S, Kadak K, Medijainen L, Karelson K. The Effects of Sodium Citrate Ingestion on Metabolism and 1500-m Racing Time in Trained Female Runners. J Sports Sci Med. 2008;7(1):125-31.

40. Zole E, Ranka R. Mitochondria, its DNA and telomeres in ageing and human population. Biogerontology. 2018;19(3-4):189-208. 
651 41. Van Deursen JM. The role of senescent cells in ageing. Nature. 2014;509(7501):439-46.

652 42. Wenz T. Mitochondria and PGC-1 $\alpha$ in Aging and Age-Associated Diseases. J Aging Res. $653 \quad 2011 ; 2011: 1-12$.

654 43. Kadlec AO, Chabowski DS, Ait-Aissa K, Gutterman DD. Role of PGC-1 $\alpha$ in Vascular 655 Regulation. Arteriosclerosis, Thrombosis, and Vascular Biology. 2016;36(8):1467-74.

656 44. Boonekamp JJ, Simons MJP, Hemerik L, Verhulst S. Telomere length behaves as biomarker of somatic redundancy rather than biological age. Aging Cell. 2013;12(2):330-

658 2.

659 45. Pfaffl MW. A new mathematical model for relative quantification in real-time RT-PCR. 660 Nucleic Acids Res. 2001;29(9):e45.

661 

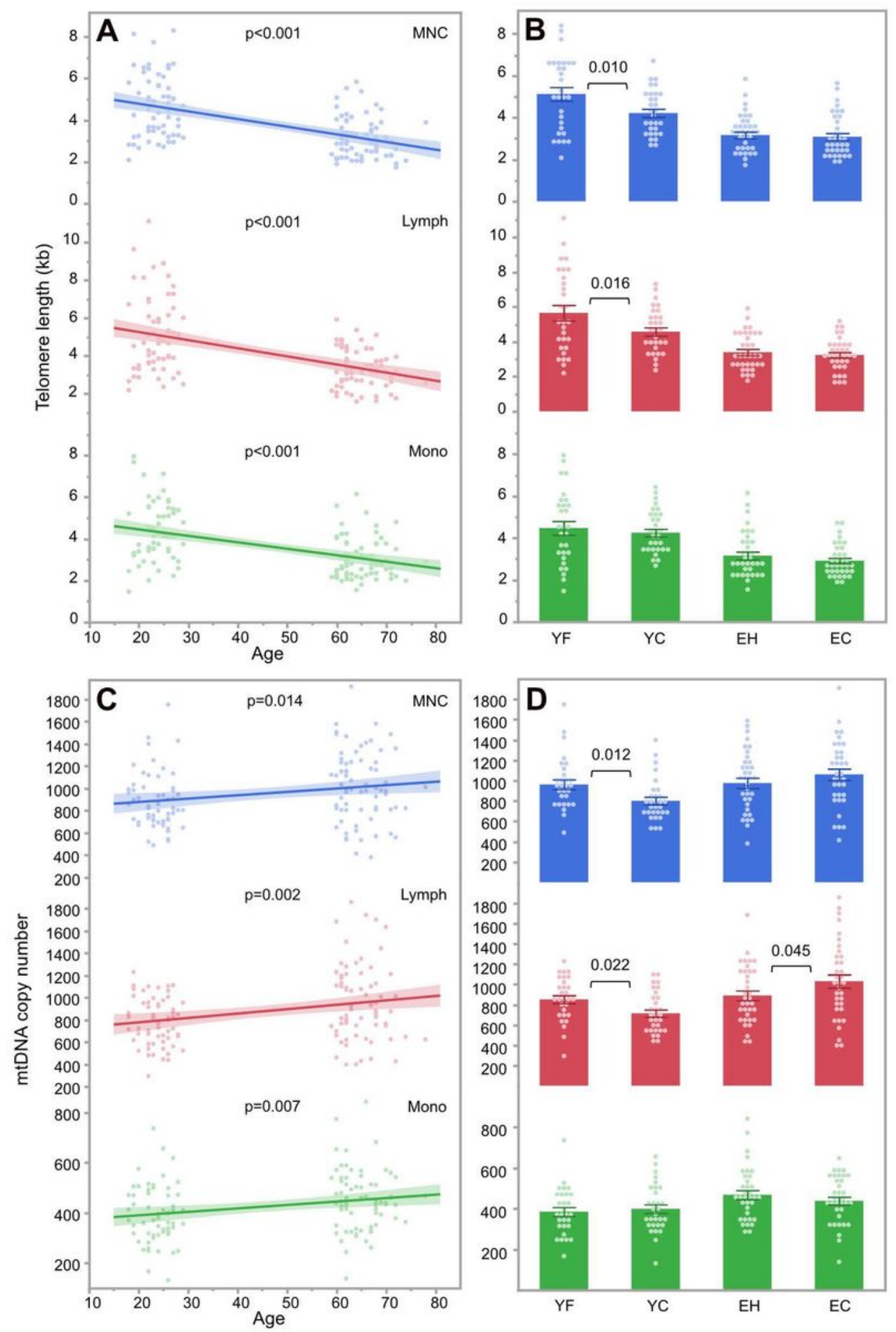

Figure 1

Correlation of telomere length with age (A) and group (B) as well as mtDNA copy number according to age $(C)$ and group $(D)$ in young football players $(Y F)$, young controls $(Y C)$, elderly team handball players (EH) and elderly controls (EC). Lymph, lymphocytes; MNC, mononuclear cells; Mono, monocytes. 

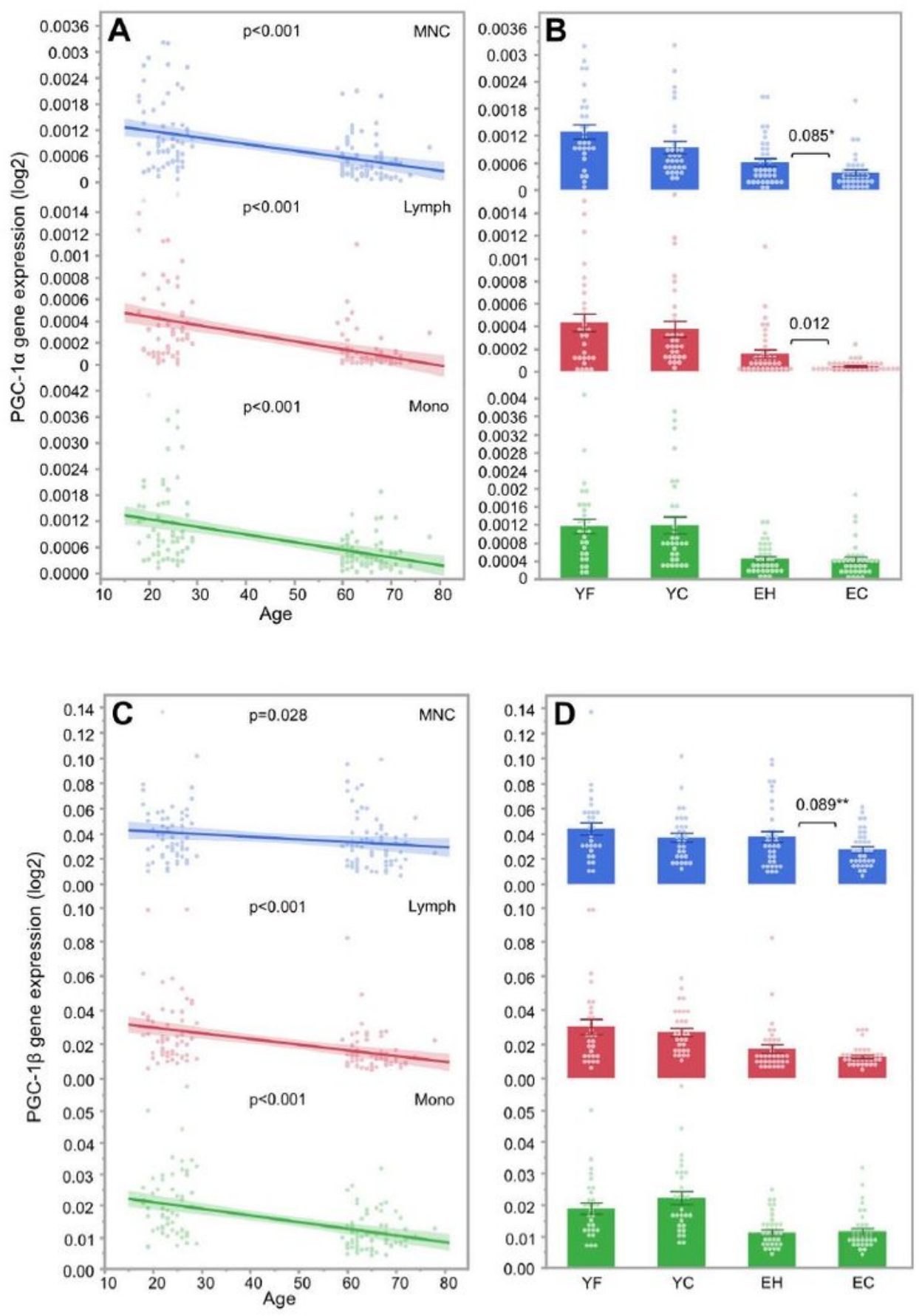

Figure 2

Correlation of mitochondrial function (PGC-1a gene expression) with age (A) and group (B) as well as PGC-1 $\beta$ gene expression according to age (C) and group (D) in young football players (YF), young controls (YC), elderly team handball players (EH) and elderly controls (EC). Lymph, lymphocytes; MNC, mononuclear cells; Mono, monocytes. ${ }^{\star} \mathrm{p}=0.041$ in univariate analysis; ${ }^{\star \star} \mathrm{p}=0.044$ in univariate analysis. 


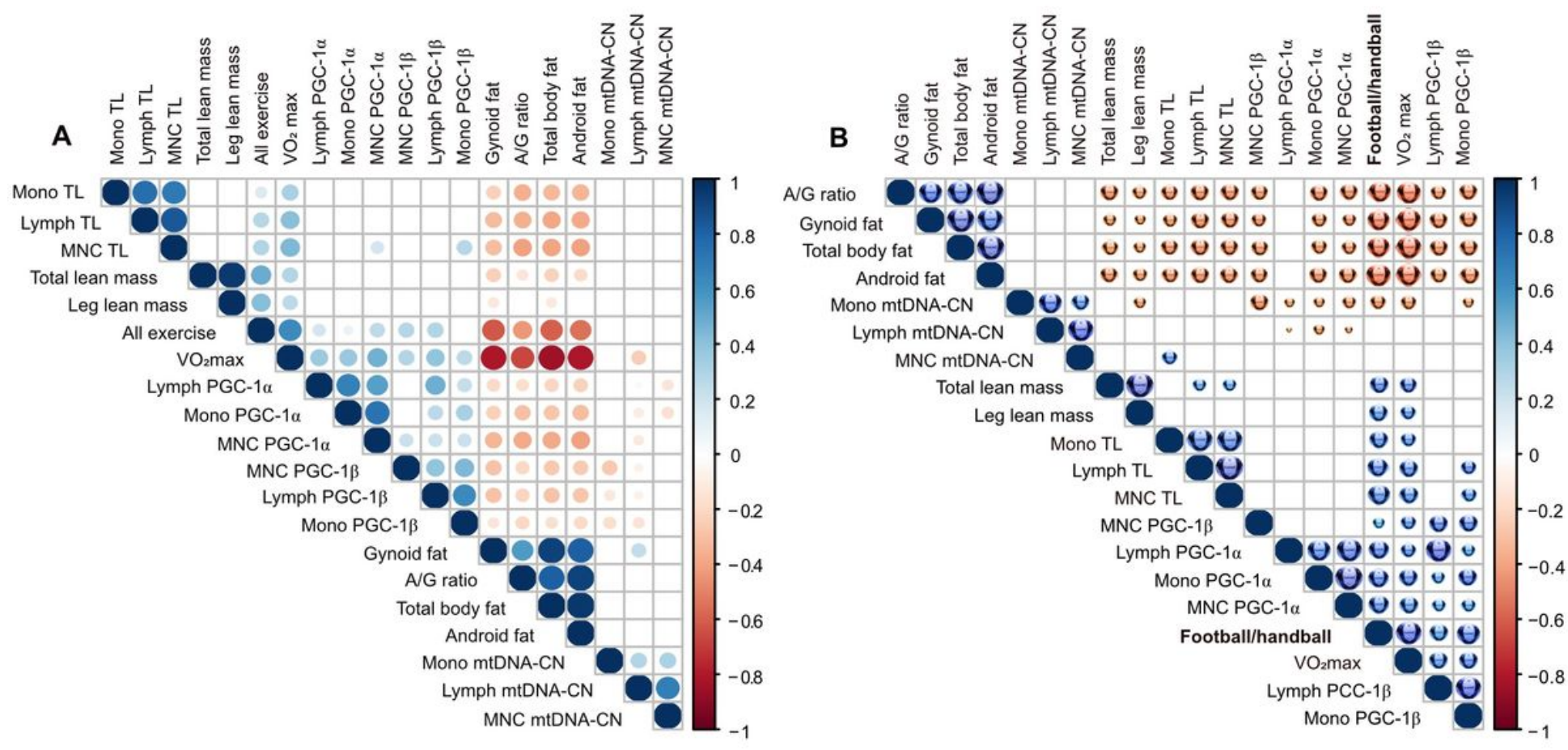

Figure 3

Spearman's correlations between the investigated variables visualised as arc diagrams in all participants (A) and in football/team handball players only (B). A/G ratio, android/gynoid fat ratio; All exercise, hours of weekly exercise of all types; Football/handball, hours of weekly football or 177 team handball training; Lymph, lymphocytes; MNC, mononuclear cells; Mono, monocytes; mtDNA-CN, mitochondrial copy number; TL, telomere length; V02max, maximal oxygen consumption.

\section{Supplementary Files}

This is a list of supplementary files associated with this preprint. Click to download.

- Hagmanetal.2021ScientificReportsSuppl.Table13.pdf

- Hagmanetal.2021ScientificReportsSuppl.Table45.pdf 